\title{
HISTORIA, DESARROLLO Y COLONIALIDAD DEL SABER EN LA ANTROPOLOGÍA PERUANA
}

Juan Rodríguez Castillón

\section{Resumen}

Se hace una revisión bibliográfica en los estudios de la antropología peruana para reconstruir su historia, desarrollo y cómo a lo largo ha seguido la práctica de importar modelos teóricos, descuidando la elaboración de marcos teóricos específicos a la realidad social peruana. Al final se plantea que una perspectiva epistémica desde posiciones étnicas y subalternas tienen mucho que aportar para la creación de modelos teóricos genuinos y para una teoría crítica descolonial.

Palabras claves: Historia de la antropología peruana, corrientes teóricas antropológicas, comunidades andinas, colonialidad del saber.

\section{Abstract}

Is a literature review in studies of the anthropology Peruvian, to reconstruct its history, development and how, throughout its history has followed the practice of importing theoretical models, neglecting the development of theoretical frameworks specific to the social reality of Peru. In the end it is proposed that an epistemic perspective from ethnic and subordinate positions have much to contribute to the creation of theoretical models for a genuine and critical theory decolonial. In the end it is proposed that an epistemic perspective from ethnic and subordinate positions have much to contribute to the creation of theoretical models for a genuine and critical theory decolonial.

Keywords: Peruvian history of anthropology, current anthropological theory, Andean communities, the coloniality of knowledge. 
Si bien el pensamiento es universal y la ciencia antropológica ecuménica, esto no impide perder de vista las particularidades en cuanto a pensamiento teórico y realidad social que nuestra disciplina produce y estudia. Tradicionalmente en el Perú la antropología ha seguido parámetros del pensamiento antropológico eurocéntrico ${ }^{1}$ norteamericano, lejos de producir un pensamiento genuino y creativo de acuerdo a la realidad sociocultural, política, económica y geográfica nacional. La regla ha sido importar modelos teóricos que los intelectuales de grandes universidades europeas y norteamericanas producen ${ }^{2}$. No solo en la antropología sino en general en la Ciencia Social peruana, ya en la década del 70 Carlos Delgado (1974) llamaba la atención de esto al decir que hasta ese momento se habían empleado conceptos, herramientas y esquemas teóricos surgidos del análisis de otras situaciones históricas y que la realidad peruana no podría ser comprendido de esta manera, pues pretenderlo sería tan absurdo como intentar comprender la realidad social de países desarrollados (Inglaterra, EE. UU., Alemania y otros) a partir de supuestos teóricos surgidos del análisis de la situación latinoamericana.

En este ensayo se pretende hacer una revisión bibliográfica de la historia de la antropología peruana, sus modelos teóricos importados y explicar a través de esto las formas coloniales del saber en ella, en tanto que centros académicos europeos sigan imponiendo las reglas del conocimiento y de la ciencia, y los intelectuales del Perú sigan reproduciéndolas.

\section{Historia de la Antropología peruana}

La antropología en el Perú como enseñanza universitaria institucionalizada se remonta a la década del 40 del siglo xx, cuando se crea la especialidad de Antropología en la Universidad Nacional San Antonio de Abad del Cusco y en 1946 en la Universidad Nacional Mayor de San Marcos, oficialmente se asigna estas fechas. Aunque Jorge Osterling y Héctor Martínez (1985) hablan de una enseñanza y práctica de la antropología peruana desde 1931 cuando se crearon en la UNMSM los institutos de Antropología y de Historia.

Ya como disciplina institucionalizada, la antropología en sus inicios toma como objeto de estudio a los pueblos indígenas a partir de los cuales los antropólogos construyen un conjunto de saberes y discursos. Luis Valcárcel, quien fue uno de los impulsadores en la formación de la antropología peruana, reconoce la importancia que tenía la disciplina en sus inicios, haciendo una distinción entre Antropología y Arqueología, dice:

\footnotetext{
1 Según Samir Amin (1983) el eurocentrismo constituye una dimensión de la cultura ideológica del capitalismo y es un culturalismo en el sentido de que supone la existencia de invariantes culturales que dan forma a los trayectos históricos de los diferentes pueblos.

2 Como dice un indígena boliviano la tendencia es repetir y emborracharse con las páginas y pensamientos que vienen de afuera. En este caso el indígena se refería al comunismo reproducido por ciertos sectores bolivianos.
} 
Para mí, la etnología era la ciencia antropológica que estudia al hombre vivo, mientras que la arqueología lo estudia muerto. Era, pues, una disciplina que urgía implantar en el Perú, donde el indígena era una fuente valiosísima para relacionar las supervivencias de las extinguidas culturas con los restos arqueológicos. Era evidente la importancia que para nuestro país habría de cobrar la etnología... sin tal fundamento, las leyes, los planes y, en general, las disposiciones de orden político, económico, jurídico o educativo, carecerían de eficacia y de positiva trascendencia (Valcárcel, 1985: 18).

Es largo el camino que ha recorrido la antropología peruana. Carlos Iván Degregori (2001), habla de 3 etapas: surgimiento, desarrollo, y fragmentación de la comunidad académica. La primera etapa es de tipo culturalista y exploradora en la que se sacraliza el trabajo de campo en las comunidades alejadas del país. Como señala Degregori: "En mayor o menor medida, el ojo imperial del etnógrafo metropolitano, se reproducía en el antropólogo urbano de clase media que llegaba a los rincones más alejados del país, esencializando al otro" (Degregori, 2001:43). El estudio de caso y las continuidades por sobre los cambios es privilegiado en esta etapa, con fuerte influencia de la antropología cultural norteamericana. Luis Valcárcel (1985) menciona el trabajo de los primeros antropólogos extranjeros como Bernard Mishkin, Harry Tschopik, quienes emprenden diversas investigaciones en el mundo andino. En 1938, Bernard Mishkin llega al Perú e inicia una prolongada investigación en la comunidad cuzqueña de Katka, en Quispicanchis. Osterling y Martínez sostienen que la llegada de antropólogos extranjeros al Perú, en especial norteamericanos, guarda relación con la creación del Instituto de Etnología y Arqueología de la UNMSM, algunos de ellos, como Julián H. Steward ${ }^{3}$, dan consejos para la creación de este instituto, donde también ejercen docencia y además participan y dirigen proyectos de antropología aplicada en el interior del Perú. Uno de ellos es el proyecto Vicos, manejado por la universidad de Cornell y el Instituto Indigenista Peruano.

El enfoque culturalista norteamericano predominante en esta primera etapa daba prioridad al trabajo de campo al estilo malinoskiano, donde el antropólogo de las ciudades reproducían las diferencias de poder en un pueblo alejado. Con este enfoque se estudia temas como el folklore, lenguaje, religión, ritual, costumbres y todos los elementos culturales e instituciones autóctonas que sobreviven en los sectores tradicionales de la sociedad peruana. Carlos Aramburú (1978) sostiene que estos temas son abordados bajo la influencia del particularismo histórico de Franz Boas, el cual se contextualiza en la ascensión del totalitarismo racista Nazi, en Europa.

3 Julián M. Steward fue director de la Smithsonian Institutium de Washington que publica el Handbook donde aparecen los principales estudios hechos sobre pobladores aborígenes de Sudamérica, y en él se reconoce la importancia de la civilización andina. El Handbook, que consiste en 7 volúmenes, fue importante puesto que su objetivo era "proveer un conciso sumario de los datos existentes y que pueda servir como referencia general para el trabajo académico..." (Osterling/Martínez, 1985: 36). 
Según Aramburú, en este contexto, la antropología asume la tarea de restablecer el valor de las culturas no occidentales y que en el Perú, el intento de reivindicar a lo indígena es un rasgo común en los estudios etnográficos de los primeros inicios de la antropología peruana. Pero, el estudio de lo indígena está en función de su esencia, disfunción o alteridad, aquellos rasgos que se podrían ubicar dentro de lo tradicional, en oposición a la modernidad europea o norteamericana. Esto tal vez con el objetivo de conocerlos en mayor profundidad en vista de que podrían ser trabas para la tarea modernizadora de occidente. Este objetivo se comprende mejor cuando se pone en marcha en 1952 el proyecto Vicos en la comunidad del mismo nombre, en el departamento de Ancash. Uno de los objetivos de este proyecto era conducir una forma de investigación experimental sobre procesos de modernización que se estaba gestando en muchas partes del mundo.

En la segunda etapa del desarrollo de la antropología peruana, que podría situarse en los años 1960 y 1970, se importan teorías como el funcionalismo, estructuralismo, dependentismo y marxismo. Según Degregori, hasta ahora no hay el desarrollo de una escuela teórica en la antropología peruana, muchos antropólogos hibridizan conceptos y métodos del estructuralismo, marxismo y funcionalismo. Orin Starn (1992), menciona que en las décadas del 60 y 70 en los EE. UU. los aspectos teóricos de la antropología giraban en torno a la antropología ecológica, de Marvin Harris y Roy Rappaport; y simbólica de Cliffor Geertz. Estos enfoques norteamericanos se hacen sentir en los estudios andinos peruanos y los antropólogos empiezan a utilizarlos para comprender temas de ecología/cultural andina, simbolismo, ritual, parentesco y cosmología. Es así que antropólogos peruanos como Flores Ochoa y otros extranjeros, enfatizan en la ecología ${ }^{4}$ y cómo el hombre andino se adapta bien a un ambiente de altura.

Los modelos teóricos de estas dos fases, mencionada por Degregori, son hasta la actualidad utilizados en la antropología peruana, muchos de estos se entrecruzan entre sí. En esta parte vamos a analizar algunos de estos modelos; centrándonos en el estructuralismo y el cultural-funcionalista y revisando el trabajo de Ossio y Billie Jean Isbell.

Por un lado el estructuralismo francés se empieza a introducir en el Perú en la década del 60. Autores como Juan Osio, Alejandro Ortiz Rescaniere, Salvador Palomino y otros, dentro de la línea de investigación de la historia andina, como N. Watchel, Tom Zuidema; reproducen el modelo estructuralista en sus estudios de caso en comunidades andinas 5 . Aquí vamos a referirnos brevemente al estudio: "La estructura social de las comunidades andinas" del antropólogo Juan Ossio.

\footnotetext{
$4 \quad$ En medio de este contexto de interés en la ecología, aparece el concepto de verticalidad ecológica de los andes planteado por Jhon Murra para describir cómo las etnias preincaicas habían controlado las tierras en diferentes "pisos ecológicos". Esto fue un aporte significativo en los estudios andinos.

5 Las comunidades andinas, muy bien estudiadas por la antropología, desde el modelo estructural se las abordan en base a oposiciones binarias.
} 


\section{La estructura social de las comunidades andinas de Juan Ossio}

En este trabajo, Juan Ossio presenta un panorama del Estado de la cuestión sobre la estructura social de las comunidades andinas, a partir de su investigación realizada en la comunidad de Andamarca (provincia de Lucanas, departamento de Ayacucho). Define a la estructura social como la disposición ordenada de las partes que conforman un todo social, y que estas partes interactúan constantemente, tejiendo y manteniendo una red de relaciones sociales, ya sean entre individuos o grupos. Esta disposición ordenada de las partes se producen en las comunidades conformadas por ayllus, las cuales ocupan un lugar determinado y entre ellas la interacción se da a partir de los trabajos comunales anuales. Esta interacción también se produce en el matrimonio, concebido por Ossio como el emparejamiento de dos individuos de sexos opuestos, lo cual expresa el ordenamiento social andino en términos dicotómicos y permite la consecución del orden social pleno.

Ossio, adoptando la idea del intercambio generalizado de Lévi Straus, caracteriza al matrimonio andino como un intercambio entre grupos sociales, que se legitima a través de tres formas rituales distintas: el primero se da en las comunidades mismas, conocido con el nombre de rimayku (conversar) ${ }^{6}$, el segundo en la iglesia católica y el tercero en el matrimonio civil. La idea del emparejamiento del matrimonio también está presente cuando entiende el parentesco ceremonial (sea bajo la modalidad del compadrazgo u otra) como un vínculo que se forja entre dos parejas o individuos diferentes, cuya práctica debe ser guiada por el respeto mutuo, lejos de suscitar conflictos entre ellas. Como vemos, aquí está presente las ideas de dicotomía, oposición, alianza, que es característico del estructuralismo. Esto también se refleja cuando habla sobre el entierro en la sociedad andina. Esto se realiza en el cementerio "que al igual que los pueblos andinos aparecen divididos en dos partes; que en este caso se vinculan con el este y el oeste" (Ossio 1977: 341), lo que también es el lado derecho e izquierdo. Esta división responde al entierro de los adultos y niños, los cuales se entierran en dos momentos diferentes (los primeros en el día y los segundos en la noche), al mismo tiempo se vincula a la idea de oposición del estructuralismo.

\section{El culturalismo de Billie Jean Isbell}

Por otro lado, el cultural-funcionalismo se puede observar en los trabajos de la antropóloga norteamericana Billie Jean Isbell. Vamos a examinar algunos de sus trabajos. En la década del 70 publica su trabajo titulado "Parentesco andino y reciprocidad: Kuyaq, los que nos aman", en este trabajo la autora describe al ritual y ceremonia del Yarqa Aspiy (limpia de acequia) en la comunidad de Chuschi (Ayacucho), este ritual es el que da inicio a un nuevo ciclo agrícola y pone en funcionamiento la reciprocidad

\footnotetext{
$6 \quad$ Esto es el arreglo matrimonial entre los padres de los que van a contraer matrimonio.
} 
andina entre los varayoq (especie de alcalde indígena) y los Kuyaq, los que aman a dicho alcalde, pueden ser sus familiares, compadres, etc. Según Isbell esta reciprocidad andina es la base del funcionamiento del prestigio de los varayoq, pues estos dependen de sus Kuyaq. En este caso se trata de una reciprocidad de tipo pública, definida como la relación social que vincula a personas con otros, esta relación constituye una serie de intercambios no solo de bienes y servicios sino de conductas. Esta relación para Isbell permitiría el funcionamiento de la sociedad andina.

En otro trabajo titulado "Para defendernos a nosotros mismos: ecología y ritual en una aldea andina", que es la comunidad de Chuschi, publicado en 1977, Isbell recurre a modelos ecológicos y simbólicos para representar el mundo chuschino ensimismado y dividido en dos segmentos sociales: los campesinos quechuahablantes y los mestizos, constituido por burócratas y profesores hispanohablantes, quienes son los malos de la película, por no guardar aprecio a las tradiciones andinas de los campesinos chushinos, quienes - a su vez- se ensimismarían o encerrarían para mantener sus tradiciones contra las presiones externas del mundo.

Los modelos teóricos importados, en especial el culturalismo, ecología cultural, simbolismo, funcionalismo y estructuralismo, al abordar y centrarse en temas como cultura, ritual, costumbres o folclor; es decir en la otredad y en las continuidades; como dice Degregori, ignoran o subestimaron los conflictos latentes en un país como el Perú. El ejemplo más claro está en el interés de Isbell, quien a pesar de haber realizado trabajos en Chuschi, lugar donde nació Sendero Luminoso en 1980, no observó los síntomas de este nacimiento por su desinterés en los conflictos, el descontento de la población, la pobreza, etc. Solo mostraba interés en temas de ritual y ecología, presentando a la comunidad de Chuschi con personas ensimismadas y aisladas del resto de la sociedad.

Esto es propio de un enfoque culturalista de la sociedad. Ahora los límites de este enfoque se pueden ver ya en la década del 80 , con el suceso en la comunidad de Uchuracay (Ayacucho) donde fueron asesinados 8 periodistas por comuneros iquichanos quienes los confundieron con terroristas de Sendero Luminoso. A raíz de este hecho se forma una comisión investigadora presidida por Mario Varga Llosa y como asesores a los antropólogos Fernando Fuenzalida y Juan Ossio. Al final de la investigación se presenta un informe donde se revela los límites del culturalismo; pues solo el informe se centra en dar cuenta de la otredad, y el aislamiento de las comunidades iquichanas dentro de una visión dualista que distingue a un "Perú profundo" de uno "oficial", como si existieran dos perúes.

\section{Aproximación explicativa a la regla de importar modelos teóricos en la Antropología}

Con lo dicho en líneas anteriores, no significa rechazar el aporte de los estudiosos extranjeros que bien han ayudado ha comprender la historia y realidad social peruana. Lo que se puede criticar es que varias generaciones de antropólogos peruanos han hecho poco por crear marcos teóricos específicos a su realidad social de origen, a 
pesar de que muchos de ellos han estudiando en grandes universidades europeas y norteamericanas.

Ya pasaron más de seis décadas desde que la antropología peruana se ha institucionalizado como disciplina; y hasta la fecha no ha habido intentos de crear una teoría propia a nivel nacional ${ }^{7}$. Con esto no se pretende aislar a la disciplina, ni encapsularlo, sino articularlo a un nivel internacional a partir de su propia creación y aporte teórico. Si los franceses aportaron y desarrollaron el estructuralismo con Lévi Strauss; y los ingleses el funcionalismo ¿qué marcos teóricos podemos aportar nosotros? ¿Qué podemos ofrecer al mundo?

Se puede afirmar que la recurrencia a teorías o paradigmas norteamericanas y europeas es una forma de entender que los investigadores sociales peruanos, han pensado que aplicar una dosis de ciencia occidental y europea era necesaria para desarrollar la antropología y las CCSS en el Perú. Lo cual no ha resultado tan mal, ya que de esta forma se ha podido realizar investigaciones muy importantes y comprender la cultura de los grupos indígenas peruanos. Como recalco, lo criticable es que no se han intentado crear modelos teóricos propios.

También esta práctica de importación de modelos teóricos es una forma de dependencia en el plano de la ciencia que tienen los países en proceso de desarrollo respecto de los más desarrollados. Tal vez es un reflejo de una dependencia general de los primeros países. El Perú, en un comienzo sujeto al poder político colonial español, en casi toda su historia republicana ha estado marcado por una dependencia de tipo económica de otros países como Inglaterra y EE. UU. Velasco Alvarado trató de romper con esta dependencia exterior, al dar más importancia a lo nacional y a los pueblos indígenas, y también a las CCSS, que se pone de moda, por su papel de sentar las bases de la reforma estructural social del país (recordemos que el sociólogo Carlos Delgado fuel el inspirador de la Ley de Reforma Agraria). Luego de Velasco y ya terminado los 70, el Perú se vuelve otra vez dependiente del capitalismo exterior. Sin embargo, este pasajero rompimiento de la dependencia, no se llevó a un nivel de discusión teórica en las CCSS peruana, para de esta forma romper con los paradigmas teóricos externos y crear formas alternas de los mismos. Es así que se seguirá realizando investigaciones con modelos teóricos de la antropología ecológica y simbólica de EE. UU. y del estructuralismo francés en los años 1970 y 1980. Más bien en otros países latinoamericanos como Brasil, la dependencia se discutirá en el nivel de las ciencias sociales, surgiendo así lo que es uno de los aportes más significativos a nivel latinoamericano: la teoría de la dependencia ${ }^{8}$, que se discutirá en las CCSS y que incide en el nivel político estatal de Brasil, al sustituirse en el plano económico el

\footnotetext{
$7 \quad$ ¿Cómo se explica esto? ¿Qué nos falta para producir teorías a partir de nuestra realidad social que pueda traspasar fronteras?

8 Su incidencia en el Perú es muy notable, pues en los 60 se aplica en el proyecto del Valle Chancay. Los autores quienes toman esta postura son Fernando Fuenzalida, Julio Cotler y Aníbal Quijano. Sin embargo, sería entrecruzado y luego reemplazado por el Marxismo que aparece en 1970. Pero según Degregori se trata de un marxismo economicista que deja muy poco espacio para tratar a la cultura.
} 
modelo de importación por el de exportación, haciéndose uso en el plano académico los conceptos de centro-periferia. A pesar de que algunos critican a esta teórica, por ser muy economicista, donde la cultura es instrumental a los procesos de acumulación capitalista (Grosfoguel, 2006), es uno de los intentos de construir una teoría a nivel latinoamericano.

Por último, la prevalecencia de modelos teóricos antropológicos norteamericanos y europeos y su reproducción por los antropólogos peruanos es una forma de colonialidad del saber en las CCSS. Como menciona Grosfoguel (2006), los Estados del centro desarrollan estrategias ideológicas/simbólicas promoviendo las formas de conocimiento occidentalistas que privilegian a occidente sobre el resto. Como consideran algunos autores de los estudios subalternos, si bien ya no estamos ante una forma administrativa política del colonialismo, podemos decir que ahora estamos ante otra forma de colonialidad, lo que podría ser de tipo camuflada, menos visible, más potente, que regula nuestras conductas, prácticas y percepciones científicas de la realidad social a partir de modelos teóricos surgidos en contextos sociales europeosnorteamericanos, que, como dice Grosfoguel, representa sus conocimientos como únicos capaces de lograr una conciencia universal, desechando el conocimiento no occidental, tildándolo de provincialista, particularista o incapaz de alcanzar la universalidad. Aquí es importante recordar lo que dijo alguna vez el antropólogo Raúl Romero, luego de comentar el discurso inaugural del IV Congreso Nacional de Investigadores en Antropología realizado en el 2005 en Lima, mencionaba las diferencias de poder entre la antropología del Perú y del resto de países en vías de desarrollo; con respecto a la antropología de los países del primer mundo; y que los antropólogos de esta área cuando vienen al Perú miran a sus pares nacionales como "bichos raros", según su propia experiencia.

Entonces, ¿cómo trascender epistemológicamente?, es decir, de descolonizarse del canon y la epistemología occidental; escapar de las formas eurocentricas y norteamericanas del saber y crear modelos teóricos alternos desde la región; y, particularmente, desde el Perú. ¿Tendríamos que regresar de nuevo al indigenismo para buscar modelos propios? Pero este de por sí no supone un modelo teórico, es decir no nos puede ayudar a explicar los múltiples problemas contemporáneos, como los conflictos sociales existentes, la desigualdad social y económica, problemas de género y de ciudadanía, entre otros. Lo que sí puede brindarnos, y desde el mundo andino y amazónico propiamente dicho, son categorías o nociones propias (como del tiempo, concepción de lo natural) a partir de las cuales se podrían crear modos de explicación y comprensión de la realidad; pero ¿limitados a un ámbito y problema particular? Esto tal vez supondría recrear un tipo de fundamentalismo reducido a lo local al igual que lo hace el eurocéntrismo, como da a entender algunos autores (como Grosfoguel) al preguntarse si ¿podemos generar conocimiento más allá de los fundamentalismos eurocéntricos y del tercer mundo? Sin embargo, se puede decir que una perspectiva epistémica desde posiciones étnicas ${ }^{9}$ y subalternas tienen mucho que aportar para la

\footnotetext{
9 Por ejemplo en el mundo amazónico, poco explorado por la Ciencia Social peruana,
} 
creación de modelos teóricos genuinos y para una teoría crítica descolonial. Esto supone deconstruir las formas del saber de los trabajos monográficos elaborados bajo los lineamientos de la episteme occidental-europea, tanto por los antropólogos de estas regiones como por los propios científicos locales, que han reproducido formas de saber importados. Y para deconstruir estos trabajos, primero tenemos que empezar a cambiar de práctica, empezar leyendo a antropólogos nacionales y latinoamericanos, y no entusiasmarnos por la novedad e ir corriendo a leer europeos, en cuanto llegue algún libro. Como decía alguien, primero hay que conocernos a nosotros mismos leyéndonos entre los nacionales y latinoamericanos.

\section{BIBLIOGRAFÍA}

ARAMBURÚ, Carlos

1978 “Aspectos del Desarrollo de la Antropología en el Perú". En Podesto, Bruno (Editor). Estado de las ciencias sociales en el Perú. Universidad del Pacífico, Centro de Investigación. Lima

DEGREGORI, Carlos y otros

2001 Enseñanza de Antropología en el Perú, Lima, CIES-IEP

DEGREGORI, Carlos Ivan (editor)

2000 No hay país más diverso: compendio de Antropología peruana. Red para el Desarrollo de las Ciencias Sociales, Lima

DELGADO, Carlos

1974 Problemas sociales en el Perú contemporáneo. Lima, IEP.

GROSFOGUEL, Ramón

2006 "La descolonización de la economía política y los estudios postcoloniales: transmodernidad, pensamiento fronterizo y colonialidad global" en Tabula Rasa. Bogotá, No 4: 17:48.

ISBELL, Billie Jean

1977 To defend Ourselves: ecology and ritual in an andean village. Austin: Universty of Texas Press.

1974 "Parentesco andino y reciprocidad. Kuyaq: los que nos aman", en

existen categorías de comprensión del mundo diferentes a las occidentales, donde el mundo natural y humano está interrelacionados. Para los pueblos de habla Arakmbut, del departamento de Madre de Dios, el término "Wandari” hace alusión a cualquier área extensa que incluye el sobre o bajo terreno, el agua y el cielo. Así las aves, los peces en el agua y los animales o los cultivos son moradores del wandari, que está dividido en tres dominios horizontales: el Ndumba (Monte), el Wawe (río) y el Tamba (chacra). Si se le pregunta a un indígena Arakmbut si le pertenece la minería aurífera del subsuelo, que el Estado dice ser dueño, responde que sí, pues el oro al estar en el monte o en el subsuelo es parte del wandari. 
Alberti, Giorgio / Mayer Enrique (comp.) Reciprocidad e intercambio en los andes peruanos. Lima, IEP.

OSSIO, Juan

1977 "La estructura social de las comunidades andinas" en Mejía Baca (ed.) Historia del Perú (3). Lima

OSTERLING, Jorge/ MARTINEZ, Héctor

1985 "Apuntes para una historia de la antropología social peruana: décadas de 1940-1980” en Rodríguez Pastor Humberto (comp.) La Antropología en el Perú. Lima, CONCYTEC

ORIN, Starn

1992 “Antropología andina: andinismo y sendero luminoso" en Allapanchis, $\mathrm{La}$ guerra en los andes, No 39, Cusco, Instituto de Pastoral Andina. Pp. 15-71.

ROMERO, Raúl

2005 "Globalidad, peruanidad y periferia" en San Marcos al Día. Lima, UNMSM.

VALCÁRCEL, Luís

1985 "Inicios de la etnología en el Perú", en Rodríguez Pastor Humberto (comp.) La Antropología en el Perú. Lima, CONCYTEC. 